\title{
Dural arteriovenous fistula post sinus thrombosis in puerperium
}

\author{
Jose Manuel Pumar • Ramón Garcia-Dorrego • \\ Maria I. Pardo • Alicia Vazquéz-Martin • Paula Sucasas
}

Received: 16 July 2010 / Accepted: 23 August 2010 /Published online: 26 October 2010

(C) The Author(s) 2010. This article is published with open access at Springerlink.com

\begin{abstract}
A 28-year-old woman had a normal delivery (primipara) on January 15, 2009. On March 20, 2009, she suffered sudden onset of severe headache. Protein-S and protein-C levels were within the normal ranges. Computed tomography on admission showed no subarachnoid hemorrhage, and the patient was discharge with analgesic treatment. Four days later the patient presented again to our emergency department with increased headache, nauseas, vomiting and bruit of the head. In view of the history and clinical evolution, an urgent computerized tomography (CT) brain scan with intravenous contrast was done showing the empty delta sign; as magnetic resonance imaging (MRI) scan was not available at that time, computed tomography in venograms (Fig. 1a,b) was performed revealing occlusion of the superior sagittal sinus and the bilateral transverse sinus. The patient was referred to the Department of Neurosurgery where a cerebral angiography confirmed sinus thrombosis (ST) and revealed a dural arteriovenous fistula (DAVF) involving the right transverse sinus fed by the branches of the right middle meningeal artery, and the right occipital artery draining through transverse and sigmoid sinuses to the straight sinus (Fig. 2a,b). Transarterial embolization with N-butylcyanocrylate and detachable coils was performed, achieving occlusion of the fistula (Fig. 3a,b).
\end{abstract}

J. M. Pumar $(\bowtie) \cdot$ R. Garcia-Dorrego • A. Vazquéz-Martin •

P. Sucasas

Neuroradiology Department of Hospital Clinico Universitario, Universidad de Santiago de Compostela,

Travesia de la Choupana s/n,

15706 Santiago de Compostela, Spain

e-mail: josemanuel.pumar@usc.es

\section{I. Pardo}

Gynecologic Department of Complejo

Hospitalario de Pontevedra,

Pontevedra, Spain
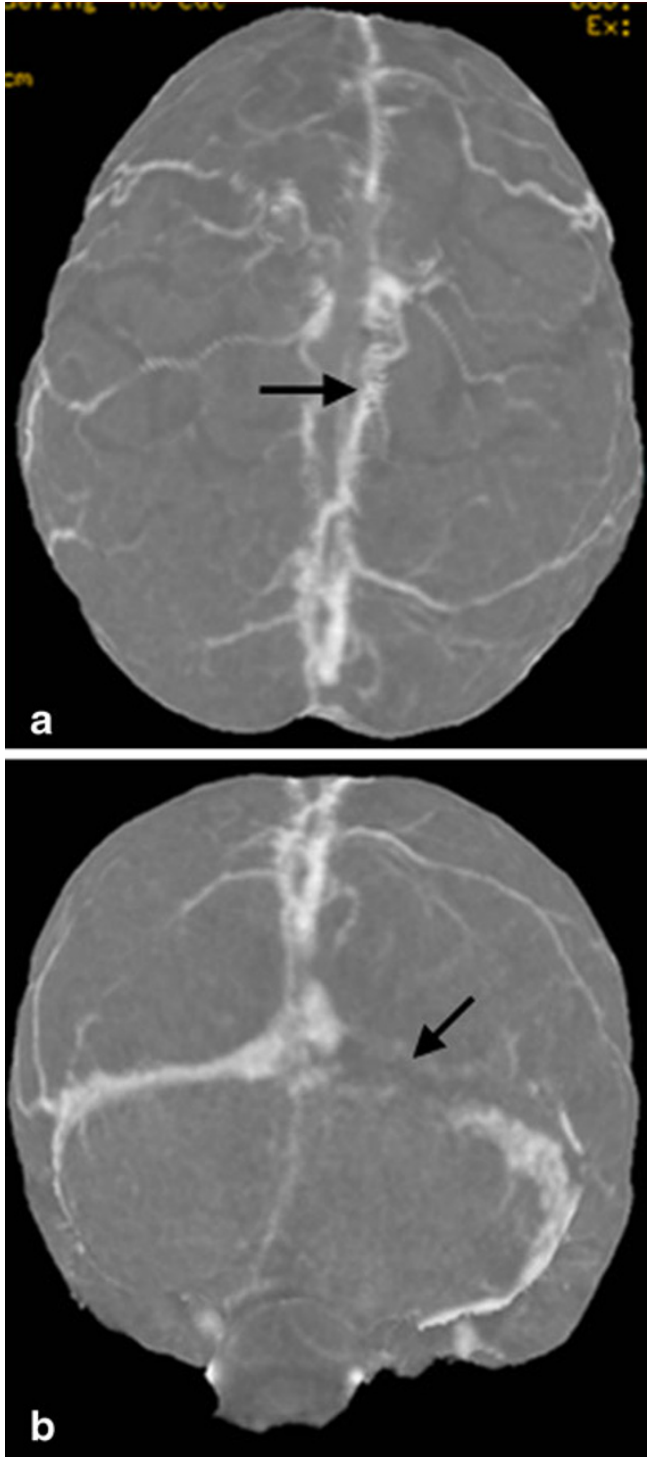

Fig. 1 Computed tomography venograms showing occlusion of the superior sagittal sinus (a) (arrow) and the bilateral transverse sinus (b) (arrow) 
Fig. 2a, b Computed reconstruction 3D imaging showing dural arteriovenous fistula (arrows)
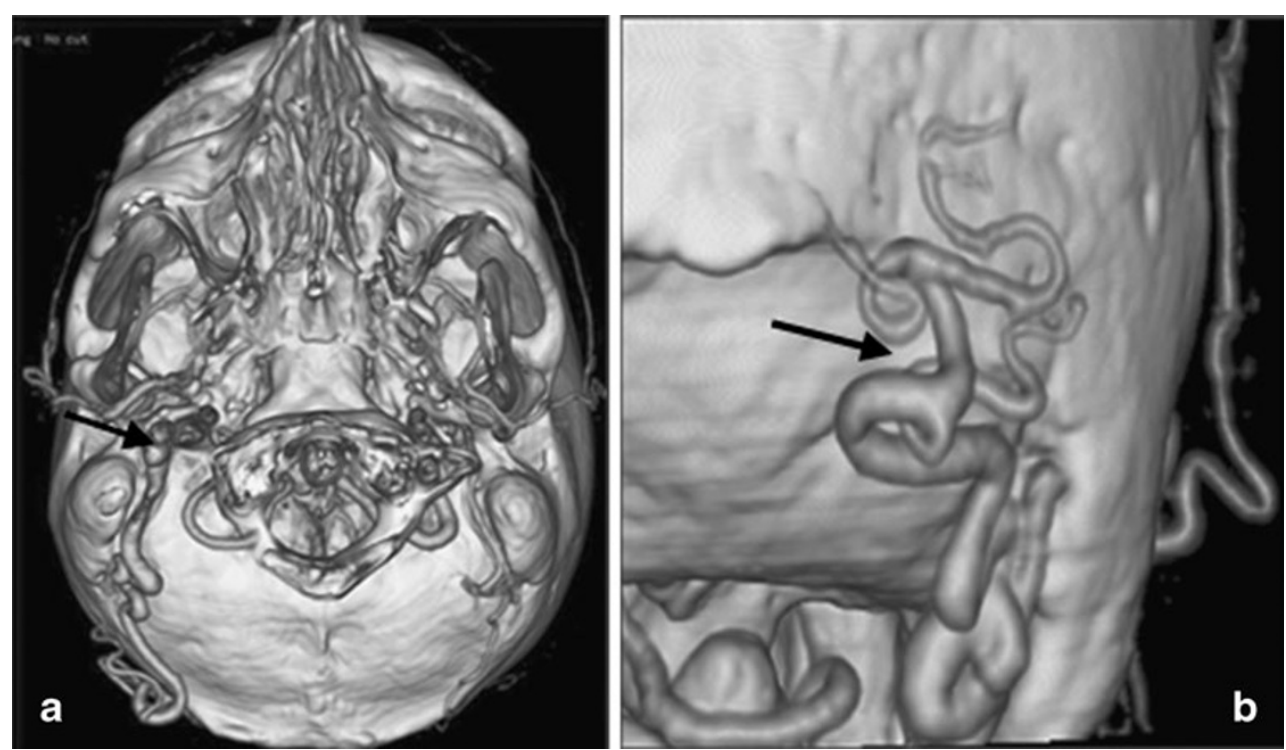

Fig. 3 Lateral right external carotid angiogram before the embolization (a) (arrow) and after the embolization (b) showing nearly complete occlusion of the fistula (arrow)
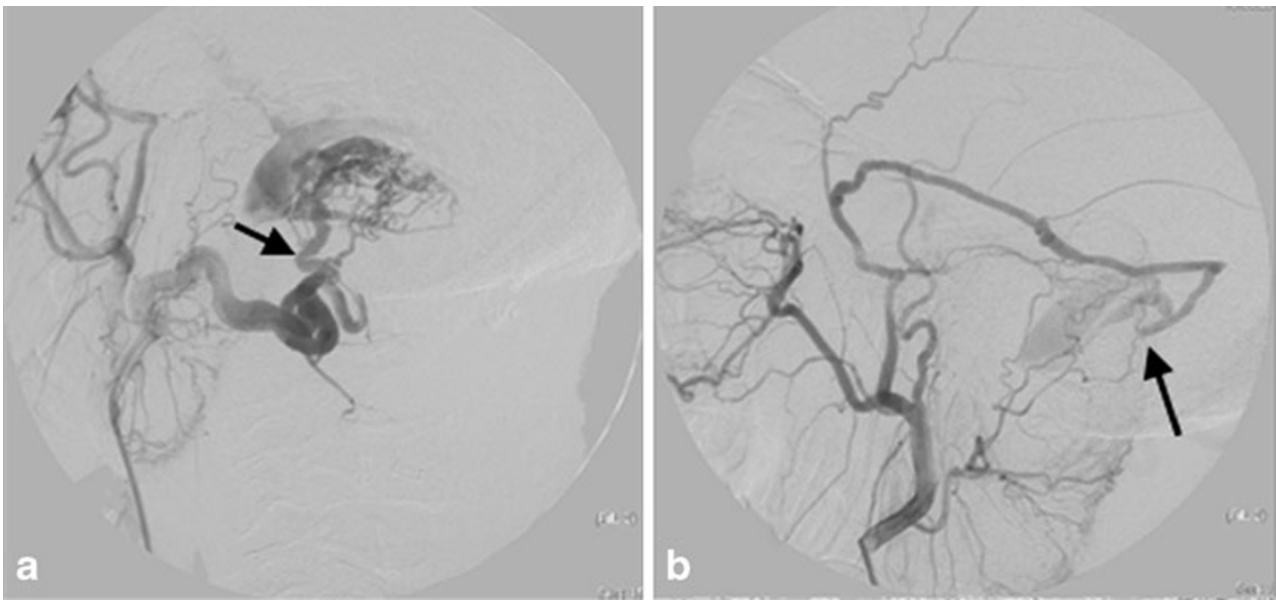

There is a clear-cut association between ST and DAF, although it may be difficult in some cases to ascertain if the thrombosis was a primary or secondary event [1]. The hypothesis proposed for the pathogenesis of DAVF is based on the physiological arteriovenous shunts between the meningeal arterial networks and the dural venous sinuses[2].

Open Access This article is distributed under the terms of the Creative Commons Attribution Noncommercial License which per- mits any noncommercial use, distribution, and reproduction in any medium, provided the original author(s) and source are credited.

\section{References}

1. Nishio A, Ohata K, Tsuchida K, Tsuyuguchi N, Hara M, Komiyama M, Tsuruno T, Murata T (2002) Dural arteriovenous fistula involving the superior sagittal sinus following sinus thrombosis. Neurol Med Chir (Tokyo) 42:217-220

2. Siddiqui FM, Kamal AK (2006) Complications associated with cerebral venous thrombosis. J Park Med Assoc 56:547-51 